\title{
Gender differences in adult-onset asthma: results from the Swiss SAPALDIA cohort study
}

\author{
Sofie Hansen ${ }^{1,2}$, Nicole Probst-Hensch ${ }^{1,2}$, Dirk Keidel ${ }^{1,2}$, Julia Dratva ${ }^{1,2}$, \\ Robert Bettschart ${ }^{3}$, Marco Pons ${ }^{4}$, Luc Burdet ${ }^{5}$, Pierre-Olivier Bridevaux ${ }^{6,7}$, \\ Tamara Schikowski ${ }^{1,2}$, Christian Schindler ${ }^{1,2}$, Thierry Rochat ${ }^{7}$ and \\ Elisabeth Zemp ${ }^{1,2}$
}

Affiliations: ${ }^{1}$ Dept of Epidemiology and Public Health, Swiss Tropical and Public Health Institute, Basel, Switzerland. ${ }^{2}$ University of Basel, Basel, Switzerland. ${ }^{3}$ Lungenpraxis, Medizinische Klinik Hirslanden, Aarau, Switzerland. ${ }^{4}$ Sede Civico, Ospedale Regionale di Lugano, Lugano, Switzerland. ${ }^{5}$ Dept for Internal Medicine, Hôpital Intercantonal de la Broye, Payerne, Switzerland. 'Service de Pneumologie, Hôpital du Valais (RSV), Centre Hospitalier du Valais Romand, Sion, Switzerland. ${ }^{7}$ Division of Pulmonary Medicine, University Hospitals of Geneva, Geneva, Switzerland.

Correspondence: Elisabeth Zemp, Socinstrasse 57, 4051 Basel, Switzerland. E-mail: Elisabeth.Zempluunibas.ch

ABSTRACT A higher incidence of asthma is reported in women compared with men, but evidence in later adulthood is limited. We aimed to determine the 20-year cumulative incidence of adult asthma in Switzerland and its relation to sex, taking into account age and allergic sensitisation.

We assessed incidence of self-report of doctor-diagnosed asthma between 1991/1992 and 2010/2011 in 5128 subjects without asthma, aged 18-60 years at baseline. The age-related probability of asthma onset was analysed by logistic regression adjusting for potential confounders and stratified by sex and allergic sensitisation at baseline.

Over 20 years, $128(5.1 \%)$ men and $198(7.5 \%)$ women newly reported doctor-diagnosed asthma. The adjusted odds ratio for female sex was 1.99 (95\% CI 1.54-2.57) overall, 3.21 (95\% CI 2.12-4.85) among nonsensitised subjects, and 1.43 (95\% CI 1.02-2.02) in sensitised subjects. The probability of asthma onset decreased with increasing baseline age in women but not in men. The higher probability of new asthma in sensitised compared with nonsensitised men was unrelated to age, whereas in women it decreased with age.

Asthma incidence was higher in women than in men but decreased with increasing age. The female predominance was considerably stronger in nonsensitised adults compared with those with allergic sensitisation.

@ERSpublications

Female predominance in new-onset adult asthma decreased with age and was more pronounced in nonsensitised subjects http://ow.ly/OaXWA

This article has supplementary material available from erj.ersjournals.com

Received: Dec 122014 | Accepted after revision: May 14 2015 | First published online: July 232015

Conflict of interest: Disclosures can be found alongside the online version of this article at erj.ersjournals.com

Support statement: This study received research support from the Swiss National Science Foundation (grants 33CS30-148470/1, 33CSCO-134276/1, 33CSCO-108796, 3247BO-104283, 3247BO-104288, 3247BO-104284, 3247-065896, 3100-059302, 3200-052720, 3200-042532, 4026-028099, PMPDP3 129021/1, PMPDP3 141671/1 and PDFMP3_137180), the Federal Office for the Environment, the Federal Office of Public Health, the Federal Office of Roads and Transport, the canton governments of Aargau, Basel-Stadt, Basel-Land, Geneva, Luzern, Ticino, Valais and Zürich, the Swiss Lung League, the canton Lung Leagues of Basel-Stadt, Basel-Land, Geneva, Ticino, Valais, Graubünden and Zürich, Stiftung ehemals Bündner Heilstätten, SUVA, Freiwillige Akademische Gesellschaft, UBS Wealth Foundation, Talecris Biotherapeutics GmbH, Abbott Diagnostics, European Commission 018996 (GABRIEL) and the Wellcome Trust (WT 084703MA). Funding information for this article has been deposited with FundRef.

Copyright @ERS 2015 


\section{Introduction}

Asthma follows an interesting gender-related life-course pattern, with higher incidence rates in boys compared with girls, a reversing of the gender ratio in puberty, and a female preponderance in early and middle adulthood [1-5]. A wide range of pathways have been proposed for this pattern [6], including genetics [7, 8], developmental factors [9, 10], hormonal changes and reproductive life histories [11-13], airway calibre [14, 15], allergic sensitisation $[2,16]$, differences in environmental exposures and susceptibility $[17,18]$, misclassification with chronic obstructive pulmonary disease (COPD) $[19,20]$ and socio-cultural factors $[21,22]$.

Asthma incidence seems to decrease with increasing age, and women are shown to have a higher incidence of asthma than men $[2-4,23]$, but there is a lack of knowledge particularly in the elderly [3, 4]. In a review by EAGAN et al. [3] in 2005, a pooled estimate of adult asthma incidence of 4.6 per 1000 person-years in women and 3.6 per 1000 person-years in men was reported. Studies allowing asthma incidence estimations for those aged $>50$ years showed an increasing trend with age overall, but sex-specific trends were less conclusive. A study from the USA in the 1990s reported a decreased incidence in both men and women aged $>65$ years [24], as did a more recent Swedish study with information up to age 75 years [4].

The age course of asthma incidence seems to differ in sensitised and nonsensitised subjects [2], which may contribute to the inconclusive findings across age. Nonsensitised asthma, which has a more severe clinical course in adults [25], appears to have a higher incidence in women than in men [2,26], but is found to be less often treated compared with sensitised asthma [27]. The number of prospective studies reporting sex-specific incidence rates into late adulthood is limited. In order to improve recognition and treatment, further investigation into gender differences in asthma in older populations is crucial.

Making use of the ongoing Swiss Cohort Study on Air Pollution and Lung and Heart Diseases in Adults (SAPALDIA), now covering 20 years of longitudinal observation of a population aged 18-60 years at baseline, we investigated the cumulative incidence of adult asthma in Switzerland and its relation to gender, taking into account age and allergic sensitisation.

\section{Methods}

Study design and population

The SAPALDIA study (see Acknowledgements section) was initiated in 1991 in eight geographically diverse areas in Switzerland (Aarau, Basel, Davos, Geneva, Lugano, Montana, Payerne and Wald). A total of 9651 persons (51\% female) aged 18-60 years participated in the baseline study (SAPALDIA 1 (S1)) after having been recruited through random population sampling. Re-assessments took place in 2002/2003 (SAPALDIA 2 (S2), $\mathrm{n}=8047$ ) and in 2010/2011 (SAPALDIA 3 (S3), $\mathrm{n}=6088$ ). Participants answered a detailed questionnaire and underwent health examinations, including blood samples for serological tests and allergy skin testing. The protocol and participation rates have been described in further detail elsewhere [28, 29]. This analysis includes 5128 subjects who reported no doctor-diagnosed asthma at baseline, provided complete information on doctor-diagnosed asthma in at least S1 and S3 and had complete covariate information (figure 1). Ethical approval was obtained from the Swiss Academy of Medical Sciences and the regional committees, and written informed consent was obtained from all participants.

\section{Definition of asthma and asthma incidence}

The primary definition of asthma incidence used for this analysis (definition 1) was the 20-year cumulative incidence of doctor-diagnosed asthma from S1-S3. Doctor-diagnosed asthma was defined as a positive answer to the questions "Have you ever had asthma?" and "Was this confirmed by a doctor?"

For the purpose of a sensitivity analysis, additional asthma incidence definitions were made based on further restriction criteria, self-report of asthma, and inconsistencies in the reporting of first attack of asthma (table 1).

\section{Sex/gender}

The main predictor of interest was self-report of being "male" or "female". We approach sex and gender as "a complex phenomenon, simultaneously biological and social" [31], and make this visible through the term sex/gender.

Age

Baseline age was categorised into six age groups of roughly 10 years for the descriptive tables. For the models, baseline age was used as a continuous variable (age in years).

\section{Allergic sensitisation}

Allergic sensitisation was defined as a positive response to the skin prick test or Phadiatop test (Phadia, Uppsala, Sweden) at baseline. A positive skin prick test was indicated by an adjusted mean wheal diameter of $\geq 3 \mathrm{~mm}$ to at least one of eight common allergens (grass, birch and Parietaria pollen, house dust mite, 
FIGURE 1 Study population. Diagram of initial population, the reasons for exclusion and the population included in the analysis.

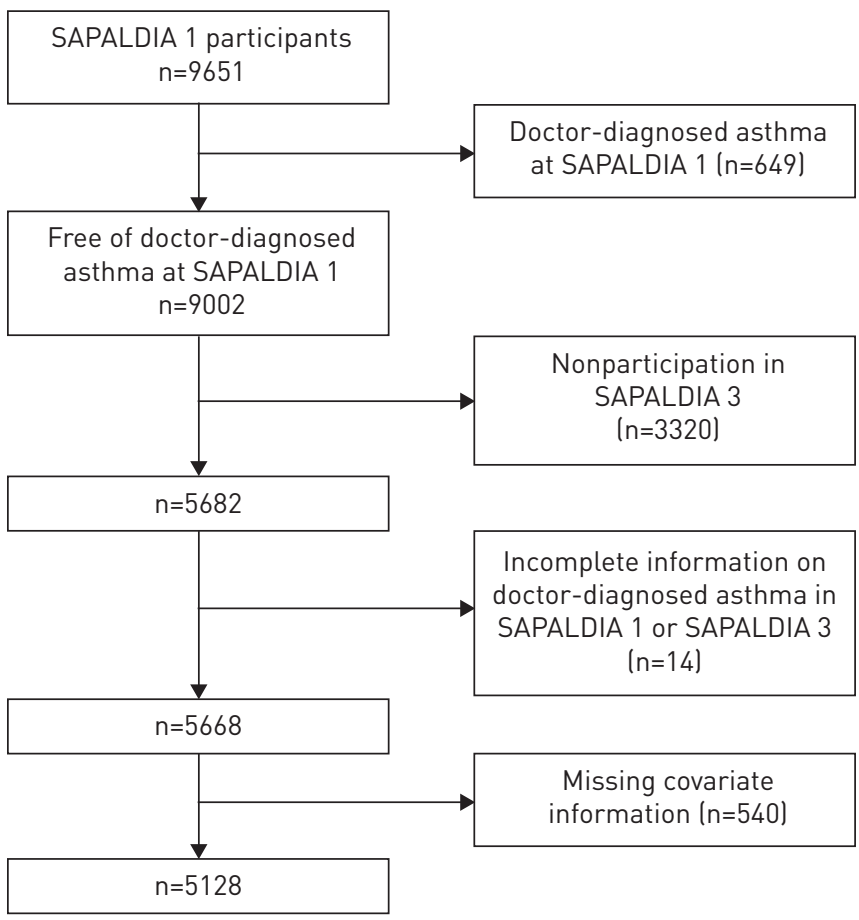

\section{TABLE 1 Definitions of cumulative asthma incidence used for main analysis and sensitivity analysis}

Name Definition Study population

Definition $1 \quad$ Cumulative incidence of doctor-diagnosed asthma from S1-S3

Outcome=1 (asthma incident case) if doctor-diagnosed asthma at S2 or S3

Outcome $=0$ (not asthma incident) if no doctor-diagnosed asthma in S2 and S3

Definition 2

Definition 1, additionally adjusting for self-report and close indicators of asthma at baseline

Definition 3a

Definition 2, additionally adjusting for asthma symptoms

Definition 3b

Definition 4

Definition 5
Combination of definitions 2 and 3a, additionally excluding anyone reporting shortness of breath or wheeze ever at baseline

Using asthma incidence definition from JACQUEMIN et al. [30] Iwhich corresponds to definition $3 b$ except the outcome is based on self-report and may reflect undiagnosed asthma)

Definition 1, additionally excluding those reporting year of asthma onset at or before baseline
No doctor-diagnosed asthma at S1

Participation in S3

Complete information on doctor-diagnosed asthma in S1 and S3

No missing covariate information

Definition 1, with addition of:

No self-reported asthma at S1

No current asthma medication at S1

No asthma attack in last 12 months at S1

Definition 2, with addition of:

No doctor-diagnosed asthma at S1

No shortness of breath of wheeze ever at S1

Exclude if at least three of the following five symptoms at S1: wheeze and breathlessness, woken up with a feeling of chest tightness, attack of shortness of breath at rest, attack of shortness of breath after exercise, or woken by attack of shortness of breath

Combination of definition 2 and $3 a$, with addition of no sob wheeze ever at $\mathrm{S1}$

Definition $3 b$ except the outcome is based on self-report

Definition 1, with addition of no asthma attack before or in 1991

S: Swiss Cohort Study on Air Pollution and Lung and Heart Diseases in Adults (SAPALDIA). 
cat and dog epithelia and the moulds Alternaria and Cladosporium) [29, 32]. The Phadiatop test, an in vitro allergy screening test, detects the presence of specific serum IgE against 11 common aero-allergens (Cladosporium, Dermatophagoides pteronyssinus, Dermatophagoides farinae, cat, dog, horse, birch, timothy grass (Phleum pratense), mugwort (Artemisia), olive, Parietaria judaica (spreading pellitory)). The percentage binding of the phadiatop was determined and results classified as positive or negative based on a cut-off of $0.35 \mathrm{kU} \cdot \mathrm{L}^{-1}[29,32,33]$. Allergically sensitised subjects with doctor-diagnosed asthma were considered as having allergic asthma.

\section{Further covariates}

Smoking status at baseline and S3 was categorised as never-smoker, former smoker and current smoker. Smoking status at S3 was defined in a cumulative way, never-smokers being consistent never-smokers across all three surveys, current smokers being smokers at S3, and ex-smokers being people who were smokers at S1 and/ or S2, but not at S3. Education was categorised into primary education (low), secondary or middle school education (intermediate), and having a technical or university degree (high). For the descriptive tables, education at baseline was used. In the models, cumulative education (the highest educational level reported at S1/S2), was used. Body mass index (BMI) at baseline was calculated as weight in kilograms, divided by the square of height in metres. Parental asthma was defined as a positive answer to the question "Did one or both of your parents ever have asthma?" Early-life respiratory infection was defined as a positive answer to the question "Did you have a serious respiratory infection before the age of 5 years?" Occupational exposure was defined as a positive answer to at least one of the items in the question "At your working place, are you currently exposed to dust/gas/smoke/aerosols/fumes/vapours?” All of these covariates were selected based on literature findings.

\section{Statistical analysis}

The 20-year cumulative incidence was calculated as the number of incident asthma cases at S2 or S3 in our sample divided by the size of the sample. The age-related probability of new onset of asthma was analysed by logistic regression adjusting for sex, BMI, parental asthma, early-life respiratory infection, occupational exposure and study area as reported at baseline, along with cumulative smoking and cumulative education as described. Analyses were also stratified by sex and allergic sensitisation in S1, to see whether the patterns of determinants differed in men and women. Up to three-way interaction terms for sex, age and allergic sensitisation were used to produce figure 2. Furthermore, we restricted the analysis to never-smokers. In order to address potential bias in loss to follow-up, inverse probability weighting was done.

We conducted several sensitivity analyses. First, we ran our model using different asthma incidence definitions as described in table 1 . Secondly, we assessed the correlation between the skin prick test and Phadiatop test using the kappa statistic and ran our multivariate analysis using only the skin prick test or Phadiatop test to define allergic sensitisation. Thirdly, sensitivity analyses were done adding the following interval exposure variables: change in smoking status, change in BMI and change in occupational exposure from S1 to S3. Finally, we addressed the separate impact of paternal and maternal asthma in the final model, ran the model also without the variable on the report of early-life respiratory infection, and furthermore we assessed urbanity as a potential confounder.

All analyses were conducted using Stata V.12 (StataCorp LP, College Station, TX, USA).
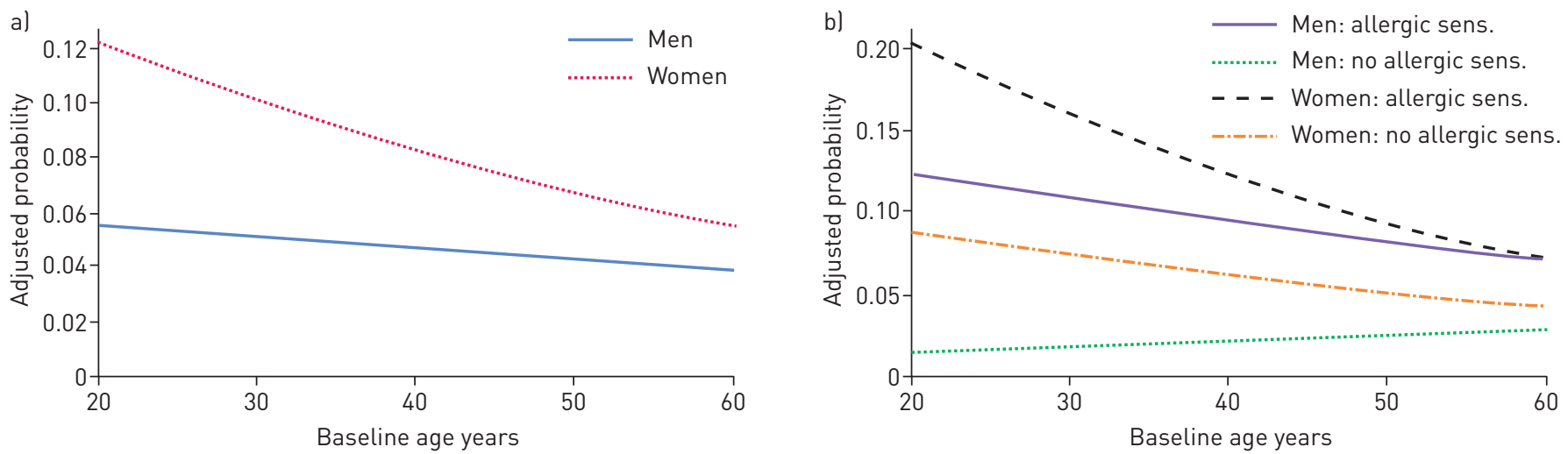

FIGURE 2 Covariate-adjusted probability of incident asthma during follow-up as a function of baseline age, stratified by a) sex, and b) sex and allergic sensitisation (sens). a) Adjusted for allergic sensitisation, body mass index (BMI), parental asthma, early-life respiratory diseases, occupational exposure, study area, cumulative smoking status and cumulative educational level, including an interaction term for sex and age. b) Adjusted for BMI, parental asthma, early-life respiratory diseases, occupational exposure, study area, cumulative smoking status and cumulative educational level, including up to three-way interaction terms for sex, age and allergic sensitisation. 


\section{Results}

Study population

Our study population consisted of 2500 men and 2628 women reporting no doctor-diagnosed asthma at S1, providing complete information on doctor-diagnosed asthma in at least S1 and S3 and having complete covariate information (figure 1). The characteristics of the study population by sex/gender are given in table 2 . There were slightly more females than males in the older age group (50-70 years). Males more frequently reported occupational exposure and higher education than females, whereas females more frequently reported early-life respiratory infections, never having smoked and lower education. Older subjects, current smokers, subjects with higher BMI and subjects reporting occupational exposure and low education were slightly more likely to be excluded (table 2).

\section{Cumulative incidence}

Over 20 years of follow-up, 326 (6.4\%) participants newly reported doctor-diagnosed asthma, 128 (5.1\%) men and 198 (7.5\%) women. Cumulative incidence was relatively stable in the sensitivity analysis using different asthma incidence definitions, ranging from $4.5 \%$ when using definition 5 to $6.4 \%$ when using definition 1 (supplementary table S1). When analysed in men and women separately, the ranges were somewhat larger (3.6-5.1\% in men and $5.3-7.5 \%$ in women).

\section{Determinants of asthma incidence}

\section{Sex/gender}

The crude odds ratio (OR) for female sex was 1.50 (95\% CI 1.20-1.87), and 1.62 (95\% CI 1.28-2.04) when adjusting for age and allergic sensitisation. In the fully adjusted analyses, the OR for female sex was 1.99 (95\% CI 1.54-2.57) (table 3), being only slightly smaller in the analyses restricted to never-smokers (OR 1.78, 95\% CI 1.18-2.67) (table 3). The likelihood of new onset of asthma decreased significantly with increasing

TABLE 2 Main characteristics at baseline comparing those excluded from study population with those included, by sex

\begin{tabular}{|c|c|c|c|c|c|c|}
\hline & \multicolumn{2}{|c|}{ Study population ${ }^{\#}$} & \multicolumn{2}{|c|}{$\begin{array}{l}\text { Excluded but asthma } \\
\text { free at } S 1^{\pi}\end{array}$} & \multicolumn{2}{|c|}{ p-value ${ }^{+}$} \\
\hline & Male & Female & Male & Female & Male & Female \\
\hline Overall & $2500(48.8)$ & $2628(51.3)$ & 1915 (49.5) & $1951(50.5)$ & \multicolumn{2}{|c|}{0.46} \\
\hline Age years & & & & & $<0.001$ & $<0.001$ \\
\hline$<30$ & $565(22.6)$ & $520(19.8)$ & 399 (20.8) & $368(18.9)$ & & \\
\hline $30-40$ & $629(25.2)$ & 715 (27.2) & $409(21.4)$ & 446 (22.9) & & \\
\hline $40-50$ & $754(30.2)$ & 759 (28.9) & 533 (27.8) & $555(28.5)$ & & \\
\hline $50-60$ & $497(19.9)$ & $565(21.5)$ & 485 (25.3) & $486(24.9)$ & & \\
\hline $60-70$ & $55(2.2)$ & $69(2.6)$ & $89(4.7)$ & $96(4.9)$ & & \\
\hline$\geq 70$ & & & & & & \\
\hline Allergic sensitisation & $849(34.0)$ & $777(29.6)$ & $552(36.6)$ & 372 (27.3) & 0.09 & 0.13 \\
\hline Smoking status & & & & & $<0.001$ & $<0.001$ \\
\hline Never-smoker & $1001(40.1)$ & $1456(55.4)$ & 569 (29.8) & $912(46.8)$ & & \\
\hline Former smoker & $649(26.0)$ & $519(19.8)$ & $481(25.2)$ & $366(18.8)$ & & \\
\hline Current smoker & $848(34.0)$ & 653 (24.9) & $862(45.1)$ & $672(34.5)$ & & \\
\hline BMI $\mathrm{kg} \cdot \mathrm{m}^{-2}$ & $24.61 \pm 3.12$ & $22.77 \pm 3.68$ & $25.09 \pm 3.63$ & $23.56 \pm 4.54$ & $<0.001$ & $<0.001$ \\
\hline Parental asthma & 205 (8.2) & 298 (11.3) & $173(9.1)$ & $196(10.1)$ & 0.33 & 0.18 \\
\hline Early-life respiratory infection & $146(5.8)$ & $215(8.2)$ & $100(5.2)$ & $144(7.4)$ & 0.39 & 0.35 \\
\hline Occupational exposure & $1005(40.2)$ & $530(20.2)$ & $849(44.5)$ & $459(23.8)$ & 0.01 & 0.00 \\
\hline Education & & & & & $<0.001$ & $<0.001$ \\
\hline Low & 223 (8.9) & $404(15.4)$ & $391(20.5)$ & $493(25.4)$ & & \\
\hline Intermediate & $1647(65.9)$ & $1923(73.2)$ & 1129 (59.2) & $1274(65.6)$ & & \\
\hline High & $630(25.2)$ & $300(11.4)$ & $388(20.3)$ & $174(9.0)$ & & \\
\hline
\end{tabular}

Data are presented as $\mathrm{n}(\%)$ or mean \pm SD, unless otherwise stated. S: Swiss Cohort Study on Air Pollution and Lung and Heart Diseases in Adults (SAPALDIA); BMI: body mass index. \#: $n=5128$; reporting no doctor-diagnosed asthma at baseline, providing complete information on doctor-diagnosed asthma in at least S1 and S3 and having complete covariate information. " : $n=3866$; having incomplete asthma information in S1/S3, having missing covariate information, not participating in S3, but being asthma free at S1 in 1991. ${ }^{+}$: using t-test for variables sex, age and BMI, and Fisher exact test for variables smoking, parental asthma, early-life respiratory infection, education, allergic sensitisation and occupational exposure. 
TABLE 3 Determinants of asthma incidence stratified by sex, in the overall study population and in never-smokers

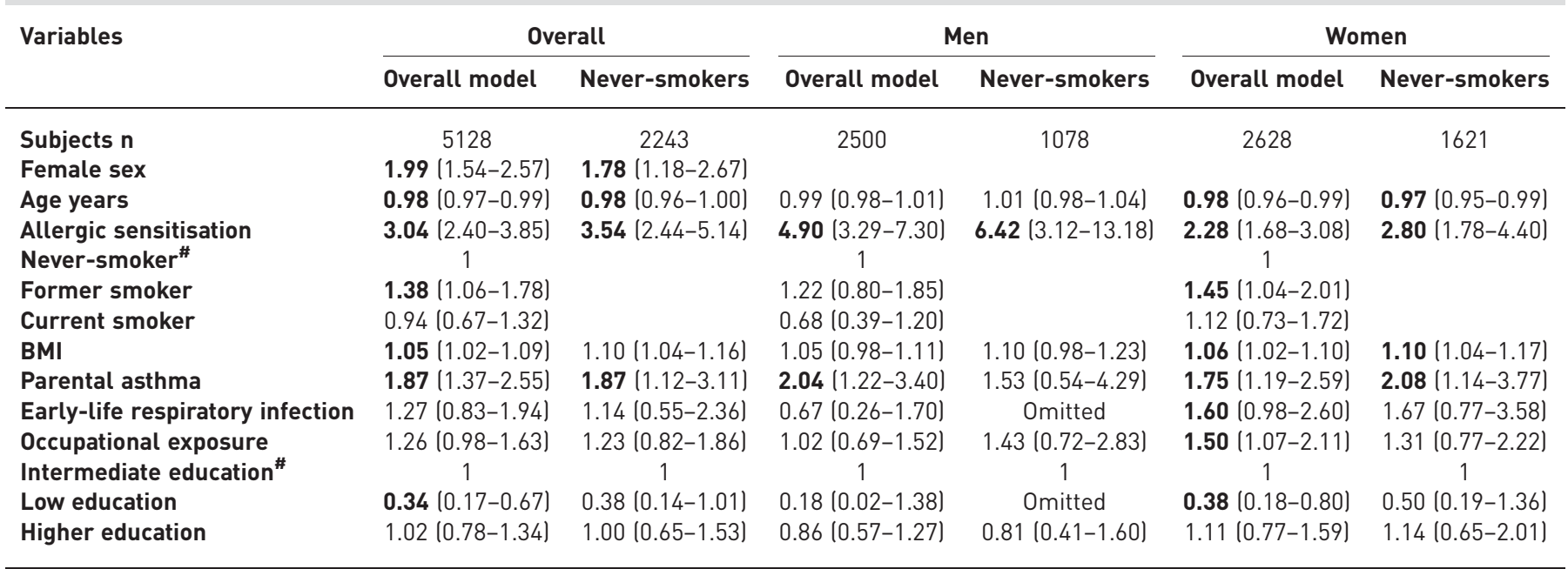

Data are presented as OR (95\% Cl), unless otherwise stated, and are based on logistic regression adjusting for female sex, age, allergic sensitisation, cumulative smoking, body mass index (BMI), parental asthma, early-life respiratory infection, occupational exposure, cumulative education and study area. Bold indicates significance at $p \leqslant 0.05 .{ }^{*}$ : reference.

baseline age. Allergic sensitisation was a strong determinant of asthma incidence (OR 3.04, 95\% CI 2.40-3.85), and parental asthma was also a relatively strong determinant (OR 1.87, 95\% CI 1.37-2.55).

\section{Stratified analysis}

In stratified analysis by sex, allergic sensitisation was a stronger predictor in men (OR 4.90, 95\% CI 3.29-7.30) than in women (OR 2.28, 95\% CI 1.68-3.08) (table 3). The probability of new onset of asthma significantly decreased with increasing baseline age in women but not in men (figure 2a). Early-life respiratory infection had a discrepant association, being protective in men and a risk factor in women. Former smokers had a higher likelihood of new onset of asthma than never-smokers (significant only in women).

Interaction analyses showed significant terms between age and allergic sensitisation in women but not in men (data not shown). When stratifying by allergic sensitisation, the OR for female sex was 3.21 (95\% CI 2.12-4.85) among nonsensitised subjects and 1.43 (95\% CI 1.02-2.01) in sensitised subjects. When stratifying by sex and allergic sensitisation, the age pattern of the association differed (figure $2 \mathrm{~b}$ ). In women, a higher probability of new asthma was seen, particularly in younger rather than in older sensitised women, whereas in sensitised men, the age-related decrease was less pronounced and in nonsensitised men, the probability slightly increased with increasing age.

When conducting inverse probability weighting for nonparticipation, results remained largely unchanged overall and in women and men separately (data not shown).

\section{Sensitivity analyses}

In the sensitivity analysis using different asthma incidence definitions, the OR values for female sex, age and allergic sensitisation were consistent across all models (table 4), being lowest when using definition 4 (1.82, 95\% CI 1.39-2.38) and highest when using definition 3b (2.08, 95\% CI 1.55-2.78). The most pronounced change observed in other covariates was in the model using definition 5 , where the OR values for allergic sensitisation and parental asthma were lowest. There was, however, no indication for effect modification by parental asthma when conducting the analysis separately for subjects with and without parental asthma using definition 5 (data not shown).

In further sensitivity analysis, we addressed whether skin prick test positivity and phadiatop positivity have a differential impact on asthma incidence. The OR values for skin prick test positivity and phadiatop positivity were very similar $(2.9,95 \%$ CI $2.29-3.71$ and $3.1,95 \%$ CI $2.44-3.94$, respectively) and the OR for female sex remained almost identical (1.97, 95\% CI 1.52-2.55 and 1.96, 95\% CI 1.51-2.55, respectively). Using interval exposure variables for smoking, BMI and occupational exposure, no significant change was observed in the female sex OR (supplementary table S2). Furthermore, we ran our multivariate analysis using paternal and maternal asthma as separate covariates (data not shown) and found paternal asthma to be a significant predictor in men and women, whereas maternal asthma was significant only in women. 
TABLE 4 Determinants of cumulative incidence of asthma using different definitions of asthma

\begin{tabular}{|c|c|c|c|c|c|c|}
\hline Variables & Definition $1^{\#}$ & Definition $2^{\pi}$ & Definition $3 a^{+}$ & Definition $3 b^{\S}$ & Definition $4^{f}$ & Definition $5^{\# \#}$ \\
\hline Subjects $n$ & 5128 & 5056 & 5009 & 4789 & 4932 & 4932 \\
\hline Female sex & $1.99(1.54-2.57)$ & $2.07(1.58-2.72)$ & $1.92(1.47-2.51)$ & $2.08(1.55-2.78)$ & $1.82(1.39-2.38)$ & $1.90(1.40-2.59)$ \\
\hline Allergic sensitisation & $3.04(2.40-3.85)$ & $2.85(2.22-3.64)$ & $3.09(2.41-3.95)$ & $2.86(2.20-3.73)$ & $2.80(2.19-3.57)$ & $2.49(1.88-3.29)$ \\
\hline Never-smoker ${ }^{\text {} 111}$ & 1 & 1 & 1 & 1 & 1 & 1 \\
\hline Former smoker & $1.38(1.06-1.78)$ & $1.35(1.03-1.76)$ & $1.40(1.07-1.83)$ & $1.37(1.02-1.83)$ & $1.30(0.99-1.69)$ & $1.29(0.95-1.75)$ \\
\hline Parental asthma & $1.87(1.37-2.55)$ & $1.74(1.25-2.43)$ & $1.98(1.44-2.73)$ & $1.95(1.37-2.77)$ & $1.71(1.22-2.39)$ & $1.47(0.99-2.18)$ \\
\hline Early-life respiratory infection & $1.27(0.83-1.94)$ & $1.30(0.84-2.03)$ & $1.23(0.79-1.93)$ & $1.31(0.81-2.12)$ & $1.35(0.87-2.11)$ & $1.30(0.78-2.17)$ \\
\hline Occupational exposure & $1.26(0.98-1.63)$ & $1.20(0.92-1.58)$ & $1.26(0.96-1.66)$ & $1.24(0.93-1.67)$ & $1.39(1.06-1.82)$ & $1.36(1.01-1.85)$ \\
\hline Intermediate education & 1 & 1 & 1 & 1 & 1 & 1 \\
\hline Low education & $\mathbf{0 . 3 4}(0.17-0.67)$ & $0.27(0.13-0.60)$ & $0.34(0.16-0.71)$ & $0.29(0.12-0.67)$ & $0.52(0.27-0.98)$ & $0.49(0.23-1.03)$ \\
\hline Higher education & $1.02(0.78-1.34)$ & $0.90(0.68-1.20)$ & $1.05(0.79-1.38)$ & $0.94(0.70-1.28)$ & $1.03(0.78-1.37)$ & $0.97(0.70-1.34)$ \\
\hline
\end{tabular}

Data are presented as OR $(95 \% \mathrm{CI})$, unless otherwise stated, and are based on logistic regression adjusting for female sex, age, allergic sensitisation, cumulative smoking, body mass index (BMI), parental asthma, early-life respiratory infection, occupational exposure, cumulative education and study area. Bold indicates significance at $p \leqslant 0.05$. \#: final model also adjusting for study area, using asthma incidence definition 1 (cumulative incidence of doctor-diagnosed asthma from Swiss Cohort Study on Air Pollution and Lung and Heart Diseases in Adults (SAPALDIA) 1-3). ๆ: final model also adjusting for study area, using asthma incidence definition 2 (same as definition 1 additionally adjusting for baseline self-report and close indicators of asthmal. ${ }^{+}$: final model also adjusting for study area, using asthma incidence definition $3 a$ (same as definition 2, additionally adjusting for asthma symptoms). §: final model also adjusting for study area, using asthma incidence definition $3 b$ (combination of definitions 2 and $3 a$, additionally excluding at baseline anyone reporting shortness of breath or wheeze ever). $f$ : final model also adjusting for study area, using asthma incidence definition 4 (definition from JACQUEMIN et al. [30]). \#\#: final model also adjusting for study area, using asthma incidence definition 5 (same as definition 1, additionally excluding those reporting year of asthma onset at or before baseline). "१!: reference.

Omitting the variable on early-life respiratory infection did not change results. Finally, we additionally controlled for urbanity in the overall model. Urbanity was a predictor for new onset of asthma (OR 1.28, 95\% CI 1.02-1.62); however, the association between female sex and asthma incidence remained identical.

\section{Discussion \\ Main findings}

Over 20 years of follow-up, 5\% of men and 7\% of women aged 18-60 years at baseline newly reported doctor-diagnosed asthma in this population-based cohort. When adjusting for relevant confounders, women were twice as likely as men to newly develop asthma. The association between sex/gender and asthma incidence was modified by allergic sensitisation and age. Nonsensitised women were three times more likely to newly develop asthma than nonsensitised men. The likelihood of new onset of asthma decreased with age. Sex/gender differences decreased with age as well, both in sensitised and nonsensitised subjects. This study is among the few to report cumulative incidence of adult-onset asthma by sex/gender in a population with a high proportion of people aged $>50$ years. The more pronounced decrease of incidence by age among sensitised compared with nonsensitised women, and the decreasing sex differences with age, are novel.

\section{Comparison with other studies}

The decreasing trend of new asthma onset with age is in contrast to the findings of the review by EAGAN et al. [3], which showed an increase of risk with greater age for studies with a wide age span and adjusted risk estimates. The age course, however, seemed less consistent in women for the two studies reporting sex-specific rates $[34,35]$. Furthermore, the age trend disappeared in one of the studies when subjects with chronic bronchitis at baseline were excluded [35], suggesting confounding of asthma incidence with chronic bronchitis in men. Our findings expand earlier SAPALDIA findings showing lower prevalence rates of asthma in men and women above compared with below age 60 years [36], and are in line with a recent Swedish study [4] showing a decrease of asthma incidence across an age range of 16-75 years in men and women overall, and in never-smokers. In our study, the negative association with age was much more pronounced among women than men. It remained significant also when restricting the analysis to never-smokers (table 3) and when excluding subjects with COPD (data not shown).

Findings from the European Community Respiratory Health Survey (ECRHS) also pointed to a differential age course by allergic sensitisation for the baseline age range of 20-44 years, with decreasing asthma 
incidence in sensitised subjects, but increasing asthma incidence in nonsensitised subjects [2]. In our study, allergic sensitisation was most influential due to the high probability of new asthma onset in the youngest sensitised women (figure $2 \mathrm{~b}$ ), possibly due to an underlying cohort effect. As suggested by JARVIS et al. [37] in 2005, the prevalence of sensitisation to any allergen differs with age and cohort, with more recent birth cohorts showing a higher prevalence of sensitisation than earlier cohorts.

The largest sex/gender difference in our study was seen in nonsensitised subjects. These findings are consistent with LEYNAERT et al. [2], who have reported a higher incidence of nonallergic asthma in women than in men throughout all reproductive years. However, LEYNAERT et al. [2] found an increase in incidence over 10 years in nonsensitised men and women, at least in the age groups $31-40$ years and $41-44$ years. It is unlikely that differences in measurement methods explain this different pattern because the same methods were applied in ECRHS and SAPALDIA except that the Phadiatop test in SAPALDIA included 11 allergens whereas ECRHS only included four [29, 38]. Although LEYNAERT et al. [2] used the Phadiatop test alone to define allergic sensitisation, whereas we used either a positive skin prick test or Phadiatop test to define allergic sensitisation, neither their sensitivity analysis using either a positive skin prick test or Phadiatop test, nor ours when we conducted our multivariate analysis with each test separately, changed results. Because earlier studies have shown that skin prick tests and serum allergen-specific IgE may not have the same biological and clinical relevance [39], we tested the correlation of these two tests in our data, finding a kappa statistic of 0.66 . Despite moderate agreement of the two tests, no change in the OR for female sex or other covariates was observed when using the skin prick test or the Phadiatop test alone. Sex/gender differences in other factors contributing to nonatopic asthma might affect the age course differently [16]. In fact, the proportion of nonatopic incident asthma cases was higher in women in ECRHS (65\%) than in SAPALDIA (46\%), as was the prevalence of occupational exposure in women of the age groups $\leqslant 30$ and $30-40$ years (35\% versus $22 \%$ ), whereas the prevalence of smoking was identical in both studies (31\%). As for BMI, the adjustment for baseline BMI and change of BMI did not affect the female OR in either ECRHS or in SAPALDIA (supplementary table S2). However, in our study, when stratifying by sex and allergic sensitisation, baseline BMI and change in BMI were predictors of asthma incidence only in nonsensitised women. Furthermore, additional control for urbanity did not change results.

\section{Strengths and limitations}

The strength of this study is its large database representing general populations from urban, rural and mountainous areas with different environmental exposure characteristics, with standardised measurements and a health questionnaire that was developed alongside the ECRHS [29, 38]. As the study is of a prospective nature, recall bias is unlikely. However, there could be a differential reporting of asthma in men and women in higher age groups, as suggested by ToRÈn et al. [4]. We can only speculate that this might have had an impact on the low probability of incident asthma in the oldest ages and the decreasing sex/gender differences with age.

A limitation of this study, as with any longitudinal study, is loss to follow-up. Nonparticipants were more likely to smoke, to have a low education and a higher BMI and more likely to report occupational exposures (table 2). Therefore, our incidence estimate may represent an underestimation. Loss to follow-up would affect the female sex ratio only if this missing information is differential for women and men or if the probability for undergoing testing for allergic sensitisation differed in men and women. As shown in table 2, we did see some differential loss to follow-up in men and women; however, this was not the case for allergic sensitisation, at least only marginally ( $\mathrm{p}=0.09$ for men). When conducting a sensitivity analysis using inverse probability weighting, it yielded largely the same results. Because, for our study population, full information on allergic sensitisation was an inclusion criterion, all women and men of our study population were tested for allergic sensitisation. We cannot rule out, however, whether subjects having allergic sensitisation or a family history of asthma or another allergic condition were more likely to undergo testing and may be overrepresented in the analytic sample. Since there exists no gold standard for asthma, any definition has limitations. We used doctor-diagnosed asthma, which has been found to have high specificity and low sensitivity [40]. Therefore, we would expect, if anything, an underreporting. Another issue is the exclusion criteria applied to have asthma-free subjects at baseline. However, we found that results were sensitive neither to the choice of these criteria nor to the use of alternative asthma definitions (table 4).

\section{Conclusion}

Overall, new onset of asthma over 20 years was positively associated with female sex in this population aged 18-60 years at baseline, and the association of sex/gender and asthma incidence was modified by allergic sensitisation and age. A higher asthma incidence was seen among sensitised persons, particularly in younger women. Gender differences in asthma incidence were most pronounced in nonsensitised subjects. A clear age-related decline of asthma incidence and a differential pattern of this decline between 
sensitised and nonsensitised subjects were significant only in women, which needs further investigation. First, the high asthma incidence observed in sensitised young women warrants explanation. Secondly, specific pathways explaining sex/gender differences should be researched, in particular in the lower age range between 20 and 40 years, where we saw the largest sex/gender differences. For this age span, the role of nonallergic pathways, such as reproductive pathologies, which have been shown to be related to asthma $[12,13]$, may be of particular interest.

\section{Acknowledgements}

SAPALDIA study directorate: N. Probst-Hensch (principal investigator; epidemiology/genetic and molecular biology), T. Rochat (pneumology), C. Schindler (statistics), N. Künzli (epidemiology/exposure) and J.M. Gaspoz (cardiology).

Scientific team: J.C. Barthélémy (cardiology), W. Berger (genetic and molecular biology), R. Bettschart (pneumology), A. Bircher (allergology), C. Brombach (nutrition), P.O. Bridevaux (pneumology), L. Burdet (pneumology), D. Felber Dietrich (epidemiology), M. Frey (pneumology), U. Frey (paediatrics), M.W. Gerbase (pneumology), D. Gold (epidemiology) E. de Groot (cardiology), W. Karrer (pneumology), F. Kronenberg (genetic and molecular biology), B. Martin (physical activity), A. Mehta (epidemiology), D. Miedinger (occupational health), M. Pons (pneumology), F. Roche (cardiology), T. Rothe (pneumology), P. Schmid-Grendelmeyer (allergology), D. Stolz (pneumology), A. Schmidt-Trucksäss (physical activity), J. Schwartz (epidemiology), A. Turk (pneumology), A. von Eckardstein (clinical chemistry) and E. Zemp (epidemiology).

Scientific team at coordinating centres: M. Adam (epidemiology), I. Aguilera (exposure), S. Braun (statistics), D. Carballo (cardiology), S. Caviezel (physical activity), I. Curjuric (epidemiology), A. Di Pascale (statistics), J. Dratva (epidemiology), R. Ducret (statistics), E. Dupuis Lozeron (statistics), M. Eeftens (exposure), I. Eze (epidemiology), E. Fischer (genetic and molecular biology), M. Foraster (epidemiology), M. Germond (statistics), L. Grize (statistics), S. Hansen (epidemiology), A. Hensel (statistics), M. Imboden (genetic and molecular biology), A. Ineichen (exposure), A. Jeong (genetic and molecular biology), D. Keidel (statistics), A. Kumar (genetic and molecular biology), N. Maire (statistics), A. Mehta (epidemiology), R. Meier (exposure), E. Schaffner (statistics), T. Schikowski (epidemiology) and M. Tsai (exposure).

The study could not have been done without the help of the study participants, technical and administrative support and the medical teams and field workers at the local study sites.

Local fieldworkers: Aarau: S. Brun, G. Giger, M. Sperisen and M. Stahel; Basel: C. Bürli, C. Dahler, N. Oertli, I. Harreh, F. Karrer, G. Novicic and N. Wyttenbacher; Davos: A. Saner, P. Senn and R. Winzeler; Geneva: F. Bonfils, B. Blicharz, C. Landolt and J. Rochat; Lugano: S. Boccia, E. Gehrig, M.T. Mandia, G. Solari and B. Viscardi; Montana: A.P. Bieri, C. Darioly and M. Maire; Payerne: F. Ding, P. Danieli and A. Vonnez; Wald: D. Bodmer, E. Hochstrasser, R. Kunz, C. Meier, J. Rakic, U. Schafroth and A. Walder.

Administrative staff: N. Bauer Ott, C. Gabriel and R. Gutknecht.

\section{References}

1 de Marco R, Locatelli F, Cerveri I, et al. Incidence and remission of asthma: a retrospective study on the natural history of asthma in Italy. J Allergy Clin Immunol 2002; 110: 228-235.

2 Leynaert B, Sunyer J, Garcia-Esteban R, et al. Gender differences in prevalence, diagnosis and incidence of allergic and non-allergic asthma: a population-based cohort. Thorax 2012; 67: 625-631.

3 Eagan TM, Brøgger JC, Eide GE, et al. The incidence of adult asthma: a review. Int J Tuberc Lung Dis 2005; 9: 603-612.

4 Torén K, Ekerljung L, Kim JL, et al. Adult-onset asthma in west Sweden - incidence, sex differences and impact of occupational exposures. Respir Med 2011; 105: 1622-1628.

5 de Marco R, Locatelli F, Cazzoletti L, et al. Incidence of asthma and mortality in a cohort of young adults: a 7-year prospective study. Respir Res 2005; 6: 95.

6 Zemp E, Hansen S, Schneider C, et al. Sex, gender and respiratory health. In: Annesi-Maesano I, Lundbäck B, Viegi G, eds. Respiratory Epidemiology (ERS Monograph). Sheffield, European Respiratory Society, 2014; pp. 125-138.

7 Dijkstra A, Howard TD, Vonk JM, et al. Estrogen receptor 1 polymorphisms are associated with airway hyperresponsiveness and lung function decline, particularly in female subjects with asthma. J Allergy Clin Immunol 2006; 117: 604-611.

8 Postma DS, Koppelman GH. Genetics of asthma: where are we and where do we go? Proc Am Thorac Soc 2009; 6: 283-287.

9 Carey MA, Card JW, Voltz JW, et al. It's all about sex: gender, lung development and lung disease. Trends Endocrinol Metab 2007; 18: 308-313.

10 Postma DS. Gender differences in asthma development and progression. Gend Med 2007; 4: Suppl. B, S133-S146.

11 Jenkins MA, Dharmage SC, Flander LB, et al. Parity and decreased use of oral contraceptives as predictors of asthma in young women. Clin Exp Allergy 2006; 36: 609-613.

12 Real FG, Svanes C, Macsali F, et al. Hormonal factors and respiratory health in women - a review. Clin Respir J 2008; 2: Suppl. 1, 111-119.

13 Macsali F, Real FG, Plana E, et al. Early age at menarche, lung function, and adult asthma. Am J Respir Crit Care Med 2011; 183: 8-14.

14 Leynaert B, Bousquet J, Henry C, et al. Is bronchial hyperresponsiveness more frequent in women than in men? A population-based study. Am J Respir Crit Care Med 1997; 156: 1413-1420.

15 Cohen J, Douma WR, Ten Hacken NH, et al. Physiology of the small airways: a gender difference? Respir Med 2008; 102: 1264-1271.

16 Goldhahn K, Bockelbrink A, Nocon M, et al. Sex-specific differences in allergic sensitization to house dust mites: a meta-analysis. Ann Allergy Asthma Immunol 2009; 102: 487-494.

17 Downs SH, Brändli O, Zellweger JP, et al. Accelerated decline in lung function in smoking women with airway obstruction: SAPALDIA 2 cohort study. Respir Res 2005; 6: 45. 
$$
\text { 67-84 }
$$
cohorts (ESCAPE). Environ Health Perspect 2015; 123: 613-621.

31 Springer KW, Mager Stellman J, Jordan-Young RM. Beyond a catalogue of differences: a theoretical frame and good practice guidelines for researching sex/gender in human health. Soc Sci Med 2012; 74: 1817-1824.

32 Wüthrich B, Schindler C, Leuenberger P, et al. Prevalence of atopy and pollinosis in the adult population of Switzerland (SAPALDIA study). Swiss Study on Air Pollution and Lung Diseases in Adults. Int Arch Allergy Immunol 1995; 106: 149-156.

33 Merrett J, Merrett TG. Phadiatop - a novel IgE antibody screening test. Clin Allergy 1987; 17: 409-416.

34 Rönmark E, Lundbäck B, Jönsson E, et al. Incidence of asthma in adults - report from the Obstructive Lung Disease in Northern Sweden Study. Allergy 1997; 52: 1071-1078.

35 Lundbäck B, Rönmark E, Jönsson E, et al. Incidence of physician-diagnosed asthma in adults - a real incidence or a result of increased awareness? Report from the Obstructive Lung Disease in Northern Sweden Studies. Respir Med 2001; 95: 685-692.

36 Wüthrich B, Schmid-Grendelmeier P, Schindler C, et al. Prevalence of atopy and respiratory allergic diseases in the elderly SAPALDIA population. Int Arch Allergy Immunol 2013; 162: 143-148.

37 Jarvis D, Luczynska C, Chinn S, et al. Change in prevalence of IgE sensitization and mean total IgE with age and cohort. J Allergy Clin Immunol 2005; 116: 675-682.

38 Burney PG, Luczynska C, Chinn S, et al. The European Community Respiratory Health Survey. Eur Respir J 1994; 7: 954-960.

39 Bousquet PJ, Castelli C, Daures JP, et al. Assessment of allergen sensitization in a general population-based survey (European Community Respiratory Health Survey I). Ann Epidemiol 2010; 20: 797-803.

40 Torén K, Gislason T, Omenaas E, et al. A prospective study of asthma incidence and its predictors: the RHINE study. Eur Respir J 2004; 24: 942-946. 